\title{
ERRATUM
}

\section{Immunology and immunotherapy of Alzheimer's disease}

Howard L. Weiner and Dan Frenkel

Nature Reviews Immunology 6, 404-416 (2006); doi:10.1038/nri1843

When published, the fifth and ninth rows of Table 2 had information missing. The corrected rows are shown below.

\section{Immune transgene or gene knockout in \\ APP-transgenic mice}

Ccl2 transgene

Ig $\mu$ knockout

(B-cell deficient)

\section{Effect}

Reference

- Increased amyloid- $\beta$ deposition by reducing amyloid- $\beta$ clearance through increased apolipoprotein $\mathrm{E}$

- No effect on total amyloid and fibrillar

- No effect on EAE-induced amyloid clearance 